\title{
FREQUENCIA DE Toxoplasma gondii EM AMOSTRAS DE TECIDOS DE FRANGOS E EM CÉREBRO DE CAMUNDONGOS
}

\author{
Caroline Araújo da Silva ${ }^{1}$; Taise Cristina Santa Barbara da Silva Queiroz ${ }^{2}$; Jadson \\ Nascimento Borges ${ }^{3}$; Kathleen de Almeida Ferreira ${ }^{4}$; Maria Vilmária Fontes Carvalho ${ }^{5}$; \\ Luciara Alves da Cruz ${ }^{5}$; Joelande Esquivel Correa ${ }^{5}$ e Aristeu Vieira da Silva ${ }^{5^{*}}$ \\ ${ }^{1}$ Bolsista PIBIC/FAPESB, Graduanda em Ciências Biológicas, Universidade Estadual de Feira de Santana , e-mail: \\ carol.adp@hotmail.com \\ ${ }^{2}$ Bolsista PIBIC/FAPESB, Graduanda em Ciências Biológicas, Universidade Estadual de Feira de Santana , \\ e-mail: taii.cristina@hotmail.com \\ ${ }^{3}$ Bolsista CNPQ, Graduando em Ciências Biológicas, Universidade Estadual de Feira de Santana , e-mail: \\ jadsonnascimento1@hotmail.com \\ ${ }^{4}$ Bolsista CNPQ, Graduanda em Ciências Biológicas, Universidade Estadual de Feira de Santana ( UEFS), e-mail: \\ kathleen_fsa@hotmail.com \\ ${ }^{5}$ Grupo de Pesquisa em Zoonoses e Saúde Pública (GPZSP)/ Universidade Estadual de Feira de Santana e-mail: \\ vilmariafontes@yahoo.com.br, luciara.cruz@bol.com.br, joelandecorreia@gmail.com,
}

*Orientador, Professor Titular do Departamento de Ciências Biológicas/UEFS; Bolsista de Produtividade em Pesquisa CNPq, e-mail: aristeuvsilva@uefs.br

PALAVRAS-CHAVE: Toxoplasma gondii ; qPCR; HRM

\section{INTRODUÇÃO}

O Toxoplasma gondii é um protozoário parasito intracelular obrigatório, classificado no filo Apicomplexa, classe Sporozoa, subclasse Coccidia, família Sarcocystidae, causador da toxoplasmose e pode ser encontrado em vários tecidos e células (exceto hemácias) e líquidos orgânicos como saliva, leite, esperma, liquido peritoneal entre outros (Neves, 1991). O T. gondii é capaz de infectar todos os animais homeotérmicos como ovinos, suínos, caprinos, aves e o homem, que participam do ciclo de vida como hospedeiros intermediários. Os felinos silvestres ou domésticos como os gatos, por exemplo, são os hospedeiros definitivos responsáveis por contaminar o ambiente com oocistos presentes em suas fezes. O T. gondii possui um ciclo de vida heteróxeno e segundo Neves (1991) possui três formas infectantes: taquizoítos, bradizoítos e oocistos.

O homem pode se infectar com o $T$. gondii pela ingestão de carnes cruas ou mal cozidas, ao beber água e leite de caprinos infectados, alimentos e vegetais contaminados com oocistos. Existem várias técnicas usadas para o diagnostico da toxoplasmose, clínicos ou laboratoriais. Podem ser feitos testes sorológicos e imunológicos que indicam o nível do título de anticorpos circulantes correspondentes a fase da doença (Neves, 1991). Atualmente se usa também o diagnóstico molecular usada para detectar DNA do parasito em amostras de tecido (Singh, 1997 apud Costa, 2013).

Com isso, esse trabalho teve por objetivo detectar $T$. gondii em amostras de tecidos de frangos, oriundos de feiras livres e pequenas propriedades, pela bioprova em camundongos e pela reação em cadeia pela polimerase em tempo real (qPCR) seguida de análise de alta resolução de curvas de dissociação (HRM) para uma sequência de DNA ribossômico de Sarcocistidae.

\section{METODOLOGIA}

Essa pesquisa foi realizada no Município de Feira de Santana no Laboratório de Analises Clínicas e Parasitologia (LAC), Grupo de Pesquisa em Zoonoses e Saúde Pública, na Universidade Estadual de Feira de Santana (UEFS). 
Amostras de pool de tecidos, fígados de frangos e do macerado de cérebro de camundongos, inicialmente inoculados com os mesmos tecidos dos frangos, em outra etapa da pesquisa, foram mantidas congeladas em tampão-fostafo.

\section{Procedimento-Isolamento do DNA}

Inicialmente as amostras de tecidos foram descongeladas, e os microtubos foram identificados (quantidade correspondente ao número de amostras a serem extraídas). Logo após foi adicionado a estes, 350 da $\mu \mathrm{L}$ solução A do Kit. Antes de acrescentar as amostras de tecido, as mesmas foram homogeneizadas no vórtex. Depois foram incubadas a $65^{\circ} \mathrm{C}$ por 10 minutos. Posteriormente foi adicionado $150 \mu \mathrm{L}$ da solução B do Kit em cada microtubo, as amostras foram homogeneizadas vigorosamente no vórtex por 1 minuto. Em seguida foi adicionado $500 \mu \mathrm{L}$ de clorofórmio a cada microtubo e novamente homogeneizados por 1 minuto. A seguir as amostras foram centrifugadas a $12.000 \mathrm{~g}$ por 15 minutos, e em seguida outros novos microtubos foram identificados, e a fase aquosa superior foi transferida para estes microtubos.

\section{Análise de curvas de dissociação de alta resolução - high resolution melting (HRM )}

$\mathrm{Na}$ detecção e amplificação de DNA de Sarcocistidae foram utilizados oligonucleotídeos para uma sequência do gene 18S do rRNA, que amplificam uma sequência de 310 a 320 pares de bases (pb). A HRM para Sarcocistidae foi padronizada para diferenciar Toxoplasma gondii, Sarcocystis neurona, Neospora caninum e Cryptosporidium parvum (Fehlberg, 2016).

\section{Análise de Dados}

As frequências absolutas e relativas de positivos aos diferentes métodos foram calculadas, bem como o intervalo de confiança a 95\%. A concordância entre os resultados do bioensaio e da HRM para detecção de T. gondii foi avaliada pelo cálculo da estatística Kappa (MacKinnon, 2000).

\section{RESULTADOS}

A qPCR-HRM foi padronizada para diferenciar Toxoplasma gondii, Sarcocystis neurona, Neospora caninum e Cryptosporidium parvum. Tanto os frangos de que se extraíram DNA dos tecidos quantos os camundongos provenientes da bioprova apresentavam anticorpos anti-T. gondii pelo método de aglutinação direta modificada (MAT). Foram analisadas 96 amostras de tecidos de frangos e 35 amostras de cérebro de camundongos. Das 35 amostras de cérebro de camundongos cinco apresentaram amplificação significativa para DNA de $T$. gondii (FIGURA 1). No entanto, entre as 96 amostras de tecidos de frangos não houve amplificação significativa para o DNA de $T$. gondii. Uma das justificativas para os resultados negativos na avaliação direta do DNA parasitário nas amostras de tecido é a dispersão dos cistos teciduais, bem como a interferência de DNA do hospedeiro na performance da qPCR.

No caso do DNA de Sarcorcystis neurona que foi um dos controles utilizados para este trabalho, o mesmo apresentou pico de melting duplo (FIGURA 2). Curvas de melting com mais de um pico podem presumir contaminação da amostra de DNA, com produção de mais de um amplicon na reação, porém, variações dentro das sequências específicas para aquele agente em análise podem gerar este modelo de resultados (Reed et al., 2007; Huguet et al, 2010; Bruzzone et al, 2013). 
FIGURA 1- Curvas de alinhamento (A) e diferenciação (B) de Toxoplasma gondii cepa RH e das amostras de cérebros de camundongos submetidos a HRM pós amplificação do gene 18S rRNA.
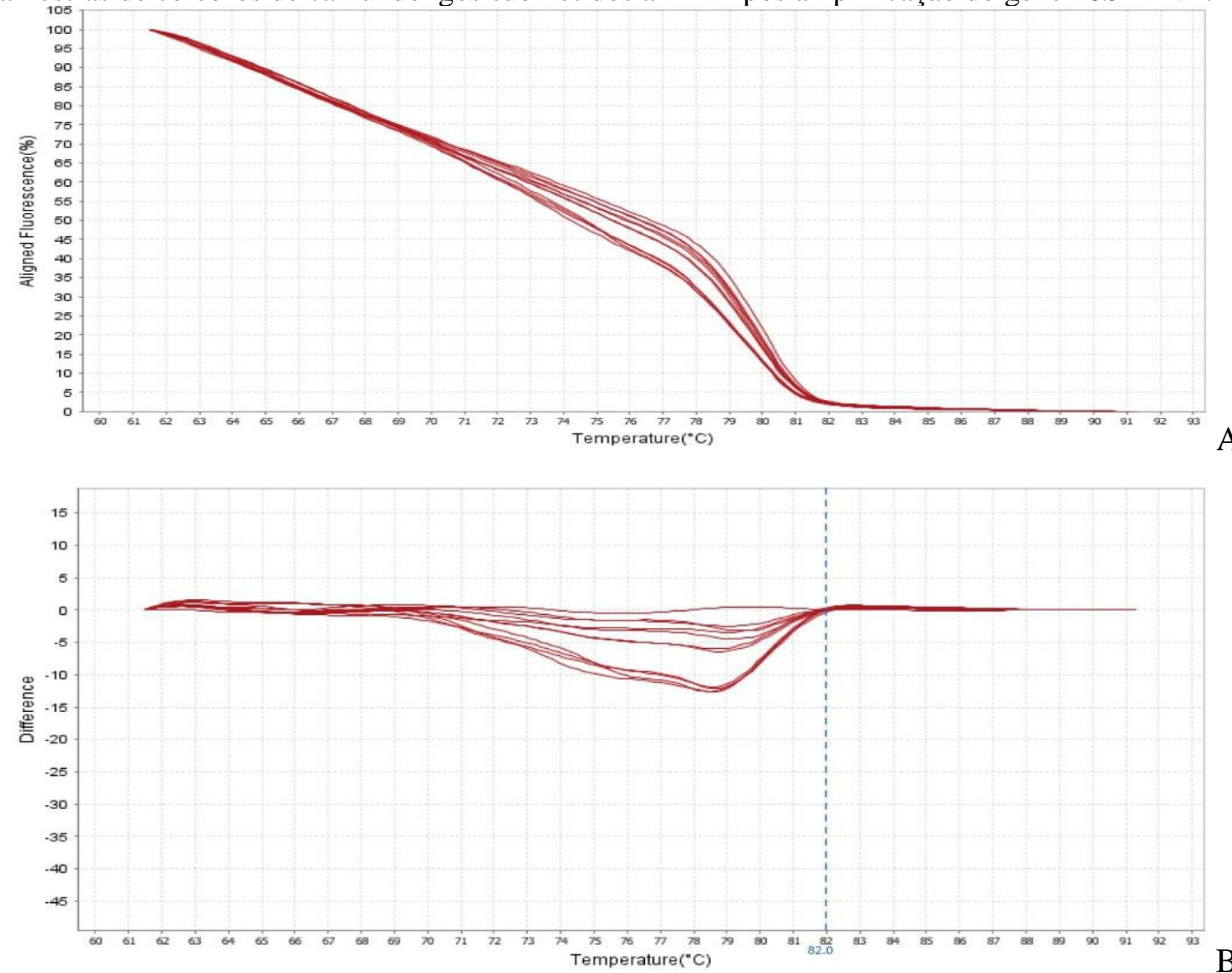

FIGURA 2- Curvas de alinhamento (A) e de dissociação (B) de Sarcocystis neurona cepa 37$\mathrm{R}$ (azul escuro) e Toxoplasma gondii cepa RH (azul claro) utilizadas como controles positivos para as análises de HRM pós amplificação do gene 18S rRNA. Feira de Santana, 2016

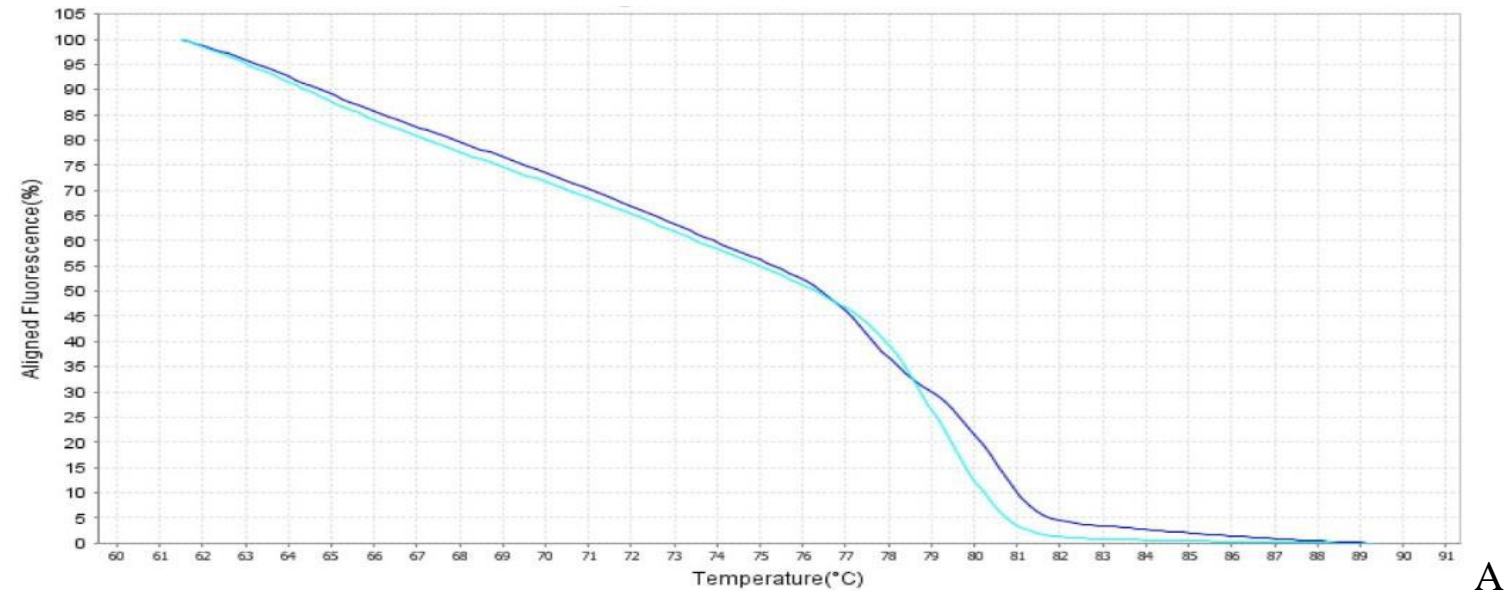




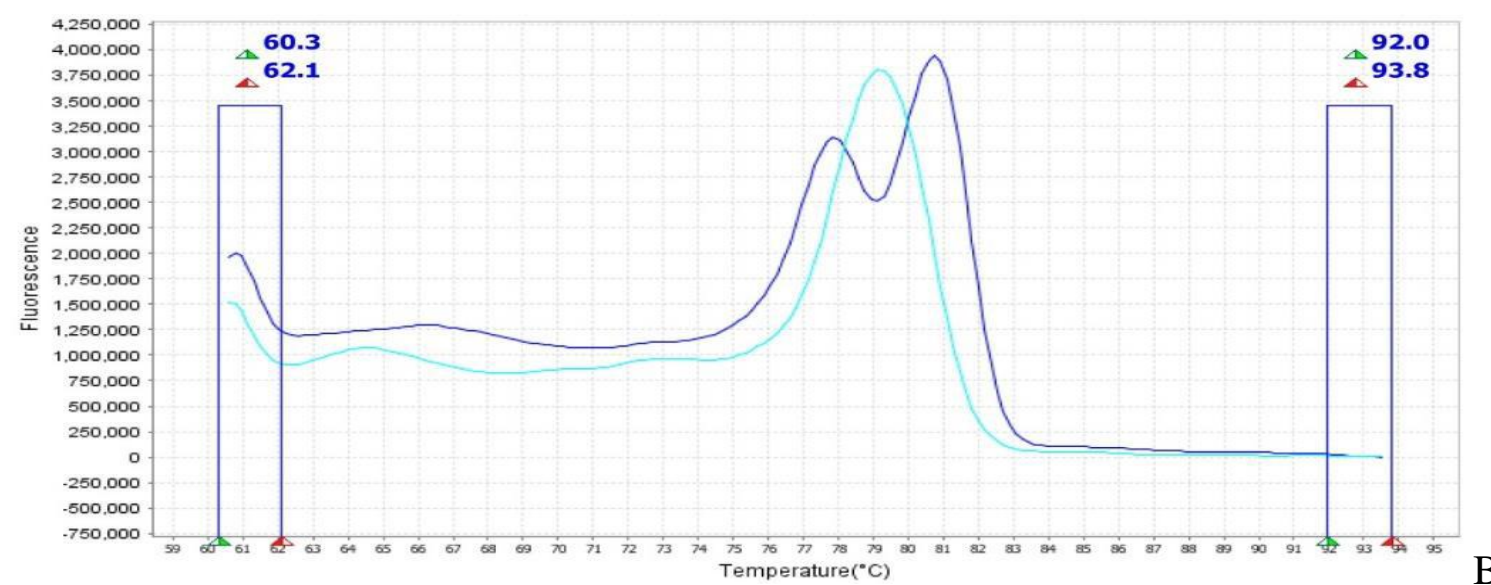

\section{CONCLUSÕES}

A PCR-HRM não detectou a presença de DNA compatível com $T$. gondii em amostras de tecidos de aves criadas extensivamente, mas houve amplificação em amostras de cérebro de camundongos inoculados com os mesmos tecidos, demonstrando que a técnica discriminou o parasito nas amostras de tecido cerebral.

\section{REREFÊNCIAS}

BRUZZONE, C.M. et al. Enhanced primer selection and synthetic amplicon templates optimize high-resolution melting analysis of single-nucleotide polymorphisms in a large population. Genet Test Mol Biomarkers, v.17, p.675-80, 2013.

COSTA, R. C .B. Aspectos epidemiológicos e importância da toxoplasmose na sanidade animal e na saúde pública. 2013. 36 f.( Mestrado)- Universidade Federal de Goiás, Goiânia.

FELHBERG, H.F. Identificação e diferenciação dos protozoários Toxoplasma gondii, Sarcocystis neurona, Neospora caninum e Cryptosporidium parvum através da técnica de High Resolution Melting (HRM). Dissertação (Mestrado em Ciência Animal). Ilhéus. Universidade Estadual de Santa Cruz. 2016. 45 f.

HUGUET, J.M. et al. Single-molecule derivation of salt dependent base-pair free energies in DNA. Proc Natl Acad Sci USA, v.107, p.15431-6, 2010.

MACKINNON, A. A spreadsheet for the calculation of comprehensive statistics for the assessment of diagnostic tests and inter-rater agreement. Comp Biol Med, v.30, p.127-134, 2000.

NEVES,P.D: Parasitologia Humana.8 ed. São Paulo: Atheneu,1991.581p

REED, G.H. et al. High-resolution DNA melting analysis for simple and efficient molecular diagnostics. Pharmacogenomics, v.8, p.597-608, 2007. 